\title{
Rigidity versus Relativity in Adverbial Syntax
}

\author{
Daniel Kaufman \\ Cornell University
}

Two diametrically opposed stances have emerged from recent theoretical debates on adverbial syntax. One approach, represented by Alexiadou (1997) and Cinque (1999), espouses a rigid hierarchy of functional projections hosting individual adverbs. The other, represented broadly by Jackendoff (1972), McConnell-Ginet (1982) and most recently Ernst (2002), takes adverb placement to be determined by the semantics of the adverbs themselves as opposed to the functional architecture of the clause. Under the latter view, adverbs may be divided into several categories based on their meaning with each category being licensed in a certain range within the sentence.

Here, I undertake a detailed examination of Tagalog adverbs and compare the predictions of the two best articulated recent theories of adverbs, that of Cinque $(1999,2004)$ and Ernst $(2002)$. The results offer support for some of the basic predictions of the semantically based approach of Ernst. Particularly important are scopal facts which do not obtain a clear explanation under a functional projection-based theory such as Cinque's.

\subsection{Two theories of adverbs compared}

Because proponents of both theories considered here employ certain ad-hoc mechanisms for handling exceptions - and are thus able to achieve similar empirical coverage - naturalness must figure prominently as an evaluation metric. 'Since each theory is suited to naturally handle a well circumscribed set of phenomena the theories under consideration must be evaluated in terms of how well the core predictions are corroborated by the data. For the purposes of the paper I will refer to the Alexiadou-Cinque theory as the Rigid Approach and Ernst's theory as the Relative Approach.

\subsection{Fundamentals and predictions of the Rigid Approach}

Cinque (1997) bases his proposal on the notion that adverb order is much stricter than can be predicted by scopal properties and semantic domains. $\mathrm{He}$ offers evidence, primarily from Romance languages, to show that ordering relations between adverbs are fixed and transitive. That is to say, if the linear relations between adverbs $A, B$ and $C$ are such that $A>B$ and $B>C$ then it is possible to conclude that $\mathrm{A}>\mathrm{C}$.

Two central tenets of Cinque's proposal are: (i) Adverbs are not adjuncts but rather specifiers within an array of strictly and universally ordered functional projections; (ii) Each adverb corresponds to an inflectional head which carries an analogous meaning. Thus, the same order is reflected by verb morphology.

Strong evidence for the specifier hypothesis is the relation between single adverbs and the verb in several Romance languages. In these languages, the verb may appear on differing sides of an adverb based on whether the verb is finite, infinitival, participial, etc. This suggests that the verb crosses certain adverbs when raising to an inflectional head. This phenomenon clearly requires a syntactic explanation (in the narrow sense) since scopally, a verb cannot be 
said to interact with a single adverb in the same way multiple adverbs interact with each other. In any case, this phenomenon is largely irrelevant in dealing with Austronesian languages since verb movement is not "gradated" as in Romance languages, i.e., we do not find overt evidence that the verb is in different positions based on finiteness or other inflectional features.

In support of a Spec-Head relationship between adverbs and verbal morphology, Cinque offers data from a wide range of languages to show that the order posited for adverbs is reflected (in reverse) in the domain of the word. Thus, an aspectual adverb, for instance, would be found in the specifier of a functional projection such as PerfectiveP while its corresponding verbal morpheme would constitute the head of this phrase.

Unexpected surface orders (i.e. those not corresponding to the underlying hierarchy of FPs) result from one of the following (Cinque 1999:34): (i) "When an AdvP directly modifies (is the specifier of) another AdvP."; (ii) "When a lower portion of the clause (containing an AdvP) is raised across a higher AdvP (for focus-presupposition requirements)."; (iii) "When one AdvP is wh-moved across another."; (iv) "When one and the same AdvP can be "base generated' in two different positions in the clause (with one of the two positions to the left, and the other to the right of another AdvP)."; (v) "When a noninherently 'focusing' AdvP (e.g. probably) is used as a 'focusing' adverb (like only and simply)."; (vi) "When an adverb is used "parenthetically"."

As Cinque notes, (iii) and (vi) are uncontroversial because they are apparent from surface form and tied to more general phenomenon. The other exception-creating circumstances, however, are more contentious in that they are less detectable and more specific to adverbs. Because of space restrictions, we focus our scrutiny on (iv) as this allowance risks proliferating functional projections to capture different interpretations of single adverbs.

The core predictions of the Rigid Approach may be summarized as the following: (i) Ordering of adverbs should be highly restricted both crosslinguistically and within single languages; (ii) Deviant orders should show the hallmarks of XP movement to a higher Spec of a functional projection (esp. FocP, TopP); (iii) Scope may often not correspond to linear order since there need not be a direct link between the scope of an adverb and its position in relation to other elements.

Cinque (2004) cites two arguments from Rizzi (2002) in support of prediction (ii). Movement of adverbs to the pragmatically unmarked ModifierP (Rizzi 2002) appears to be subject to Relativized Minimality effects (1-2). ${ }^{3}$

\section{Rapidamente, qualcuno farà sparire i documenti}

Quickly, someone will make the documents vanish

*Rapidamente, qualcuno probabilmente farà sparire i documenti Quickly, someone will probably make the documents vanish

In addition, this displacement appears to be clause-bounded (3) (adapted from Cinque 2004:703 ex. 39-41), unlike focalization and topicalization (4-5). ${ }^{4}$

(3) * Rapidamente, credo che qualcuno farà sparire i documenti Quickly, I think that someone will make the documents vanish 
RAPIDAMENTE, credo che qualcuno farà sparire i documenti

Quickly (focus), I think that someone will make the documents vanish

In regard to prediction (iii), Cinque is not precise about how the relative scope of adverbs is to be derived. This is a major point of divergence between the two theories since, for the Relative Approach, scope is the primary determinant in the positioning of adverbs of the same class. For Cinque, adverbs that are generally understood to have variable scope in relation to other scope sensitive material (e.g. frequency adverbs) are generated in unique positions in the hierarchy. Support for the Rigid Approach, therefore, may come in the form of adverbs that may obtain several scopal interpretations from one "canonical" surface position.

\subsection{Fundamentals and predictions of the Relative Approach}

Three principles within Ernst's system which contrast with the Rigid approach are the following: (i) Adverbs are adjoined freely, constrained only by general restrictions on adjunction; (ii) Sentences are composed incrementally from several semantic layers and there exists a minimal correspondence between semantic layers and syntactic phrases in the clausal architecture; (iii) An adverb is uninterpretable if it cannot access the semantic layer it requires from its position in the sentence. This happens, for instance, when a lower level adverb (e.g. Manner) is composed after a higher level adverb (e.g. Speech Act).

Ernst (2002) develops a theory of adverbs in the former tradition of treating them as adjunctions. Applying a more articulated theory of propositional semantics (based largely on Parsons 1990), Ernst is able to restrict the positions of adverbs according to what type of semantic layer, or Fact-Event-Object (FEO), they may modify. FEOs are thus treated as the semantic arguments of adverbs. Based on their semantic class, adverbs are specified to take particular FEO types and are capable of shifting that type as a result of composition. Composition is a step-wise process and layers are added under syntactic sisterhood. The basic FEO types/layers employed are the following:

$$
\text { Speech-Act }>\text { Fact }>\text { Proposition }>\text { Event }>\text { Specified Event }
$$

The constraints on how these types combine, together with ostensibly universal syntactic principles, are understood to be responsible for the distribution of adverbs within the clause. A bare verb is associated only with the lowest FEO type (the Event) which must eventually be built into a Speech Act by the time the sentence is complete. This, however, is not a strictly unidirectional process which corresponds directly to phrase structure. Rather, FEO types can raise independently on either side of the predicate and thus adverbs should show similar linear and scopal effects on either side of the verb. One important mitigating factor is the special connection between clausal Predicational adverbs and the syntax. According to Ernst, clausal predicational adverbs are subject to the same syntactic restrictions as predicational heads and thus follow the similar ordering principles. This is posited to account for the fact that these 
adverbs regularly precede the verb cross-linguistically. Non-predicational adverbs are not bound by such syntactic restrictions and therefore display a wider range of potential positions.

Adverb movement falls under the scope of more generally accepted cases of movement such as topicalization, wh-movement, clefting, etc. Under this view, then, there is no independent motivation for adverb movement and thus it should not be considered a separate "type" of movement on par with those mentioned above. Nor should there exist special phrases to host adverbs such as Rizzi's (2002) ModifierP. ${ }^{5}$ For Ernst, the only strict correspondence between FEO types and specific syntactic projections is that only eventinternal modification is possible within the "L-syntax" (i.e., corresponding to VP pace Hale \& Keyser 1993). This entails that adverbs adjoined within VP can only receive limited interpretations (e.g. manner, measure).

Ernst proposes a semantically motivated taxonomy of adverbs which have their own FEO selection requirements and which may yield different FEO types upon composition. For example, epistemic adverbs such as probably may be represented as [FACT $_{\mathrm{F}} \mathrm{ADV}$ [PROP $\left._{\mathrm{P}}\right]$ indicating that they take a Proposition as their complement and yield a Fact (cf. Parsons 1990 for discussion of these terms).

The building up of propositions and the composition of adverbs follows the FEO calculus. The primary principle of this is that any FEO type may be freely converted to any higher FEO type; but not lowered (Ernst 2004:761, 2002:50). In principle, the FEO type of a sentence fragment may be lowered through composition but this is very rare (and may also probably be subject to a non-lowering analysis). In general, adverbs and operators either raise the FEO type or maintain it. Because the FEO type may be freely raised without overt operators, an adverb that selects for a higher FEO type such as Fact or Speech-Act need not occur at a syntactically designated peripheral position but can rather be accommodated in more internal positions through FEO type raising (modulo VP-internal positions, the domain of event-internal modification).

The manner/clausal ambiguity with adverbs such as clearly as in (7) results from the fact that manner adverbials are composed via the Manner Rule. This is a rule which obligatorily applies to predicational adverbs within Lsyntax and which may optionally apply to constituents of the Event type (although a clausal reading is preferred outside of VP).

John clearly saw everything written on the chart.

(He saw it clearly $\sim$ Clearly, he saw it.)

The relevant predictions of the Relative Approach are summarized as the following: (i) An adverb that selects for a lower FEO type should not appear higher than one which selects for a higher FEO type; (ii) The positions in which an adverb is licensed should constitute a contiguous range w.r.t. nonFEO-type changing material; (iii) Adverb scope should be reflected by surface order in a concentric fashion with the predicate as the center due to the symmetric manner in which semantic layers are built in the FEO calculus. 


\subsection{Tagalog adverbs}

Tagalog offers a good testing ground for the predictions of the two theories as Tagalog adverbs are introduced into the clause by means of overt markers that elucidate their syntactic position.

The lowest attachment of adverbs is marked with nang; the same particle employed to introduce internal arguments. Manner adverbials are typically introduced in this way as can be seen in (8). Here we see that the position of the manner adverb is free within the post-verbal domain and that the various positions are interpreted uniformly. ${ }^{6}$

(8) P-in-ag-aral-an (nang maigi) ng piloto $(\checkmark)$ ang mapa $(\checkmark)$ PRF-TR-study-LV nang well GEN pilot SUB map

'The pilot studied the map thoroughly.'

(9) P-um-asok (nang madalas) sa opisina $(\checkmark)$ si Ben $(\checkmark)$ AV.PRF-enter nang often OBL office P.SUB B.

'Ben went to the office often.'

Adverbs may also be introduced in the same way as topics, that is, in clauseinitial position preceded by the marker ay. Compare the topicalization construction in (10) with the adverbials in (11) and (12).

(10) Ang tubero ay nag-trabaho sa kusina. SUB plumber TOP AV.PRF-work OBL kitchen 'The plumber, worked in the kitchen.'

(11) Kadalasan ay hindi siya p-um-apasok sa klase usually TOP NEG 3sg.SUB <AF>IMPF.enter OBL class 'Usually, he doesn't come to class.'

(12) Malamang ay nan-daya sila probably TOP AF.PRF-cheat 3p.SUB 'They probably cheated.'

Whereas we see from the above that adverbs may be marked as arguments, it is also possible to introduce adverbs in the same way as adjectives, that is, directly adjacent to the modified head with the linker $n a /-\eta$. Compare (13) and (14).

(13) Madalas na pag-ulan. frequent LNK NOMZ-rain 'Frequent rain.'

(14) Madalas na umuulan.

frequent LNK AV.IMPF-rain

'It rains frequently.'

For this type of modification, adjacency is required between the adverbial and the verb as shown by the ungrammatical (15). ${ }^{7}$ 


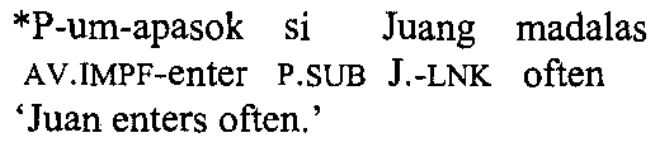

Adverbial notions are also often introduced syntactically as clefted adjectives. Strictly speaking, these should not be considered as adverbials at all since syntactically and semantically such constructions are indistinguishable from adjectival predicate constructions. However, the fact that this is the only way to express certain adverbial notions in Tagalog is instructive and thus merits inclusion here.

(16) Malinaw na mag-sasalita mamaya sa miting si Bobong. clear COMP AV-IRR.speak later OBL meeting P.SUB Bobong 'Clearly, Bobong will speak later at the meeting.' (or, 'It's clear that Bobong will speak later.')

Other adverbs may be introduced into the clause without any marker at all. The adverbs which allow this are typically mono-morphemic (not containing the $m a$ - adjectival prefix) and may also occasionally be treated as clitics, being positioned within the second position clitic cluster.

$$
\begin{aligned}
& \text { B-in-atíkos (uli) siya ( } \checkmark) \text { ng mga guro }(\checkmark) \text {. } \\
& \text { PV.PRF-criticize again 3s.SUB GEN PL teacher } \\
& \text { 'He was criticized again by the teachers.' }
\end{aligned}
$$

(18) K-um-agat sa kanya (kahapon) ang aso ( $\checkmark$ ) AV.PRF-bite OBL 3s.OBL yesterday SUB dog 'The dog bit him yesterday.'

Finally, there is the class of clitic adverbs that is restricted to appearing in second position (19-21). These consist of aspectual, mood, evidential and functional adverbs. A small number of adverbs that fall in this class may also appear in topic position as the first occurrence of sana 'OPTM' in (21) does.

B-um-alik na nga po pala sila! AV.PRF-return already EMPH POL SURP $3 p$.SUB 'They really already returned!'

(20) Mag-tatago pa rin ba kaya kayo? AV-IRR.hide still also Q RHET 2p.SUB 'I wonder, will you still hide?'

(21) (Sana ay) g-um-radweyt (sana) siya ngayon. OPTM TOP AV.INF-graduate OPTM 3s.SUB now 'Hopefully, he'll graduate.'

We are now in a position to look at the relation between adverb types and positions in Tagalog. Sentences (22-25) show the positional possibilities of an ambiguous clausal/manner adverb. 
Malinaw 'clear(ly)': (i) Manner reading - [SPeCEVEnt ADV [SPECEVEnT]]

(ii) Evidential reading - [state ADV [ Facr $]]$

(22) [TP K-um-akanta $\mathrm{ka}_{\mathrm{j}}$ [ $\mathrm{VP}_{\mathrm{i}} \mathrm{t}_{\mathrm{j}}$ nang malinaw ngayon]]

AV.IMPF-sing 2s.SUB nang clear now

'You're singing clearly now.' ( $\neq$ 'Clearly, you're singing now.')

(23) [TP Malinaw kang [TP $_{j}$-um-akanta ${ }_{i}\left[\mathrm{vP}_{\mathrm{i}} \mathrm{t}_{\mathbf{j}} \mathrm{t}_{\mathbf{j}}\right.$ ngayon $\left.]\right]$ clear 2s.SUB-LNK AV.IMPF-sing now

'You're singing clearly now.' ( $\neq$ 'Clearly, you're singing now.')

(24) [Topp Malinaw ay [Tr k-um-akanta $\mathrm{k}_{\mathrm{i}} \mathrm{ka}_{\mathrm{j}} \quad$ [VP $\mathrm{t}_{\mathrm{i}} \mathrm{t}_{\mathrm{j}}$ ngayon]]] clear TOP AV.IMPF-sing 2s.SUB now

'Clearly, you're singing now.' ( $\neq$ 'You're singing clearly now.')

(25) [тP Malinaw [cP na [TP k-um-akanta $\mathrm{ka}_{j}$ [VP ti t ngayon]]] clear COMP AV.IMPF-sing 2s.SuB now

'Clearly, you're singing now.' ( $\neq$ 'You're singing clearly now.')

The adverb in (22) represents the nang (internal argument-like) attachment showing that only a manner reading is possible from this position; (23) shows the adverb adjoined like an adjective in the preverbal position; (24) exemplifies the adverb in topic position; (25) an adverbial meaning is obtained through an adjectival predicate with a clausal complement. Note that there is a difference in the readings between (22-23) on the one hand and (24-25) on the other hand. In the former group the adverb can only obtain a manner interpretation while in the latter group the adverb can only obtain a clausal interpretation. Generally, the argument-like nang attachment of adverbs necessitates a manner reading. The positional possibilities for a modal adverb are shown in (26-29).

$$
\begin{aligned}
& \text { Malamang 'probably': modal adverb - } \left.{ }_{\mathrm{FACT}} \mathrm{ADV}\left[{ }_{\mathrm{PRO}}\right]\right] \\
& \text { *[TP K-um-akanta }{ }_{i} \text { siya }_{j} \text { [ } \mathrm{vP}_{\mathrm{P}} \mathrm{t}_{\mathrm{i}} \mathrm{t}_{\mathrm{j}} \text { nang malamang ngayon]] } \\
& \text { AV.IMPF-sing 3s.SUB nang probably now } \\
& \text { *[FocP Malamang siyang } \quad \text { [TP k-um-akanta } a_{i} \quad\left[\mathrm{VP}_{\mathrm{i}} \mathrm{t}_{\mathrm{j}}\right. \text { ngayon]] } \\
& \text { probably 3s.SUB-LNK AV.IMPF-sing now } \\
& \text { [TopP Malamang ay [Tr k-um-akanta }{ }_{i} \text { siya }_{j}\left[\mathrm{VP}_{\mathrm{i}} \mathrm{t}_{\mathrm{j}} \mathrm{t}_{\mathrm{j}}\right. \text { nayon]] } \\
& \text { probably TOP AV.IMPF-sing 3s.SUB now } \\
& \text { 'Probably, he's singing now.' } \\
& \text { [TP Malamang [CP na [TP k-um-akanta }{ }_{i} \quad \text { siya }_{j} \quad\left[\mathrm{VP}_{\mathrm{i}} \mathrm{t}_{\mathrm{j}} \mathrm{t}_{\mathrm{j}}\right. \text { ngayon]] } \\
& \text { probably COMP AV.IMPF-sing 3s.SUB now }
\end{aligned}
$$

A summary of the possible positions (excluding predicate position) for several types of adverbs is given in Table $1(\mathrm{~m}=$ manner interpretation; $\mathrm{c}=$ clausal, ep $i$ $=$ epistemic, deo $=$ deontic). 
Table 1. Summary of adverb type-position relations

\begin{tabular}{|c|c|c|c|}
\hline & \multicolumn{3}{|c|}{ [TopP ADV ay [TP ADV (clitic) [VP nang ADV]]] } \\
\hline $\begin{array}{l}\text { a. Pure manner } \\
\text { i. mahigpit 'tight(ly)' }\end{array}$ & 40 & $\checkmark m$ & $\checkmark m$ \\
\hline $\begin{array}{l}\text { b. Manner/clausal } \\
\text { i. malinaw 'clear(ly)' }\end{array}$ & $\checkmark c$ & $\checkmark m$ & $\checkmark m$ \\
\hline $\begin{array}{l}\text { c. Exocomparative } \\
\text { i. ganito 'like this' }\end{array}$ & $\checkmark c$ & $\checkmark m$ & $\checkmark m$ \\
\hline $\begin{array}{l}\text { d. Subject oriented } \\
\text { i. kusang-loob 'willingly' }\end{array}$ & $\checkmark$ & $\checkmark$ & $\checkmark$ \\
\hline $\begin{array}{l}\text { e. Functional-quant. } \\
\text { i. madalas 'often' } \\
\text { ii. kadalasan 'most often' }\end{array}$ & $\begin{array}{l}\checkmark \\
\checkmark\end{array}$ & $\begin{array}{l}\checkmark \\
*\end{array}$ & $\begin{array}{l}\checkmark \\
*\end{array}$ \\
\hline $\begin{array}{l}\text { f. Modal } \\
\text { i. dapat 'should' } \\
\text { ii. malamang 'probably' }\end{array}$ & $\begin{array}{l}\checkmark \text { epi. } \\
\checkmark\end{array}$ & $\begin{array}{l}\checkmark \text { deo. } \\
*\end{array}$ & * \\
\hline $\begin{array}{l}\text { g. Speech act } \\
\text { i. sa madaling salita 'briefly' }\end{array}$ & $\checkmark$ & * & * \\
\hline
\end{tabular}

What emerges clearly from Table 1 is that the clause appears to be bifurcated at the edge of TP. Differences in interpretation and grammaticality are found to relate to the boundary marked by the topic position. As seen in (ac), manner readings are only found within TP. Modals present a divergence from the pattern as they are the only category that may appear at the edge of TP but not within VP. The TP boundary is still relevant however since the deontic reading is highly favored within TP while the epistemic reading is favored outside of TP. Although it is difficult to make a direct connection between event-internal modification and deontic modality, the restricted readings for modals should be tied to the fact that the lower range does not allow access to higher FEO types. Finally, a number of adverbs cannot appear within TP at all.

The facts in Table 1 support two of Ernst's claims: that manner readings are restricted to (but free within) a lower domain and that clausal predicative adverbs are linearized in relation to their FEO complements in accordance with the general head-complement pattern of head-initial languages. This latter claim is supported by the fact that clausal adverbs such as (f.ii) and (g) in Table 1 can only appear as topics, preceding the entire TP complement.

Two deviations from Ernst's theory should be noted here. The edge of event-internal modification appears to be higher than VP and subject oriented adverbs such as 'willingly' are not expected to surface in the domain of eventinternal modification. I will not offer an explanation for these facts here as they do not affect the more far-reaching debate between the two theories.

\subsection{Evidence for Relativity}

While the facts shown in the previous section suggest a good deal of freedom, they do not provide an iron-clad argument for relativity in and of themselves since there always exists the possibility of movement. In this section I will present evidence which bears directly on the issue of relativity. 
4.I Syntactic locality versus the FEO calculus

As seen above, a frequency adverb such as madalas 'often' may be introduced in several different positions in the clause as seen in (30-32).

(30) Um-uulan nang madalas dito AV .IMPF-rain nang often here 'It rains often here.'

(31) Madalas ay um-uulan dito often TOP AV-IMPF.rain here 'It rains often here.'

(32) Madalas um-uulan dito often AV-IMP.rain here 'It rains often here.'

Crucially however, these positions are limited with the presence of another adverb. The modal clitic adverbs sana 'hopefully' and yata 'perhaps' appear in the second position of the clause as in (33) and (34).

(33) B-um-isita sana si Juan.

AF.PRF-visit OPTM P.SUB Juan

'Hopefully, Juan visited'

(34) B-um-isita yata si Juan.

AF.PRF-visit EPST P.SUB Juan

'Perhaps Juan visited.'

Whereas a frequency adverb such as 'often' may be found in topic position when it occurs alone as in (32), the presence of a modal adverb seems to block the possibility of madalas in topic position as seen in (35-37).

(35) Madalas ay b-um-isita si Juan often TOP AF.PRF-visit P.SUB Juan

'Juan visited often.'

(36) *Madalas ay b-um-isita sana si Juan often TOP AF.PRF-visit OPTM P.SUB Juan

(37) *Madalas ay b-um-isita yata si Juan. often TOP AF. PRF-visit EPST P.SUB Juan

That this is not a categorical constraint on the co-occurrence of these adverbs is seen from (38) and (39) where the frequency adverb is attached within TP.

(38) B-um-isita sana si Juan nang madalas AF. PRF-visit OPTM P.SUB Juan nang frequent 'Hopefully, Juan visited often.' 
Unlike Cinque's similar examples in (1-5) above, there can be no Relativized Minimality account here for two reasons. First, however these adverbs are characterized, it is doubtful that yata can be the same kind of element as madalas since madalas can appear in Spec positions and may be modified while yata cannot. Second, as a prosodically positioned Wackernagel clitic, yata is ordered at $\mathrm{PF}$ and therefore cannot interfere with syntactic movement.

These facts are expected under Ernst's analysis which does not rely on movement but rather on the FEO calculus to rule out sentences such as (36) and (37). Specifically, the presence of modal adverbs (yata, sana) convert the FEO type to Fact while a frequency adverb (madalas) requires a lower type (e.g., Event/Proposition). The prosodic domain within which the clitics are positioned is the TP, excluding the Topic. It is therefore unambiguous that the adverb in topic position must be composed after clitics within TP.

\subsection{Concentric scope phenomena}

Key evidence for Ernst's theory comes from scope facts and, in particular, data which shows that outer adverbs scope over inner adverbs on both sides of the predicate. The predictions of symmetric semantic composition are borne out by the Tagalog data. Observe the relative scope of scope of bigla 'suddenly' and lagi 'always' within the TP (40-41). When both adverbs precede the verb, the leftmost adverb must scope over the adverb to its right.

$$
\begin{aligned}
& \text { Biglang laging na-lulungkot si Juan } \\
& \text { suddenly-LNK always-LNK STA-IMPF.sad P.SUB Juan } \\
& \text { 'Suddenly, Juan is always sad.' (suddenly>always only) }
\end{aligned}
$$
Laging biglang na-lulungkot si Juan always-LNK suddenly-LNK STA-IMPF.sad P.SUB Juan 'Juan is always suddenly sad.' (always $>$ suddenly only)

Crucially, when the adverbs "sandwich" the predicate as in (42), either reading is available. This shows that adverb scope does not necessarily abide by an asymmetric left-to-right hierarchy.

$$
\begin{array}{lll}
\text { Biglang na-lulungkot } & \text { si Juan lagi } \\
\text { suddenly-LNK STA-IMPF.sad } & \text { P.SUB Juan always (ambiguous) }
\end{array}
$$

On the right edge of the clause we find the same effects. When two (non-clitic) adverbs appear following the verb, the outer one must scope over the inner. Compare the relative scope of the adverbs dalawang beses 'twice' and di-sinadya 'unintentionally' in (43) and (44).

(43) S-in-ingil nila ako nang di-sinadya nang dalawang beses PV.PRF-charge 3p.GEN 1s.SUB nang NEG-intentional nang two-LNK times 'They charged me unintentionally twice.' (twice>unintentionally only) 
S-in-ingil nila ako nang dalawang beses nang di-sinadya PV.PRF-charge 3p.GEN 1s.SUB nang two-LNK times nang NEG-intentional 'They charged me twice unintentionally.' (unintentionally>twice only)

When the adverbs flank the verb both readings are possible as seen in (45).

Dalawang beses nila akong s-in-ingil nang di-sinadya two-LNK times 3p.GEN 1SUB-LNK PV.PRF-charge nang NEG-intentional 'They twice charged me unintentionally.' (ambiguous)

Under the Relative theory, the ambiguity of (45) is predicted since such a configuration may correspond to two different bracketings in the FEO structure:

$$
\text { [E } \text { Dalawang beses [Enila akong siningil nang di-sinadya }]=(43)
$$

$\left[\mathrm{E}^{\prime}[\mathrm{E}\right.$ Dalawang beses nila akong siningil $]$ nang di-sinadya $]=(44)$

Cinque (1999:25) discusses similar English data from Andrews 1983, reanalyzing the original adjunction derivation along the lines of the specifier theory. To capture the scope facts of English (48) he posits the existence of two separate base positions for twice, a higher position with an "iterative" meaning and a lower position with a "repetitive" meaning. In (48a), the entire clause has raised to the left of the iterative twice.

(48) a. John knocked on the door intentionally twice. $=$ twice $>$ intentionally

b. John knocked on the door twice intentionally, = intentionally $>$ twice

By positing two projections for twice, Cinque seems to mistake a simple scope alternation for a more fundamental difference in meaning. His distinction between iterative and repetitive only emerges clearly when there is a second adverbial to scope under or over. Furthermore, his approach requires positing multiple phrases for every adverb that displays similar concentric effects (e.g. almost, again, always etc.) leading to an almost endless array of projections with essentially identical content. From a technical standpoint, there is also the problem of explaining why the higher twice is marked in its base position even for the iterative meaning ("John twice knocked on the door"). Unmotivated movement of the VP plus PP constituent is necessary to derive the unmarked order.

Another point for Relativity comes from the fact that two readings of often, which Cinque attributes to base generation in two different functional projections, are both present in the right edge of the clause in the reverse order which Cinque posits. ${ }^{8}$ Because of the nang marker, lower and higher attachment of adverbs is overtly distinguished on the right periphery. In the higher attachment in (49), the adverb takes wide scope over negation while in (50) it takes narrow scope.

(49) Hindi siya s-in-ingil(,) dalawang beses

NEG 3s.SUB PV.PRF-charge two-LNK times 'He wasn't charged twice.' (twice $>\mathrm{NEG}$ ) 
There seems to be no principled explanation why "repetitive" twice could not raise over negation to FocP (51a) or TopP (51b) with the adverbial being interpreted in its reconstructed position (as suggested by Cinque) beneath negation. However, the data shows that this is impossible since twice can only be interpreted in (51) with wide scope in regard to negation.

(51) a. Dalawang beses siya hindi s-in-ingil two-LNK times 3s.SUB NEG PV.PRF-charge

b. Dalawang beses ay hindi siya s-in-ingil two-LNK times TOP NEG 3s.SUB PV.PRF-charge (twice $>\mathrm{NEG}$ )

Again, this is predicted by the linear order of the adverbial and negation in regard to the verb. Because negation must be composed with the predicate before twice, the former must take narrow scope.

\subsection{Epistemic versus deontic readings of modals}

Similar to the repetitive/iterative division, Cinque proposes that epistemic and deontic readings of modals are the result of base generation in two different functional projections. He takes the fact that two instances of the same modal can occur simultaneously as evidence for the existence of two separate functional projections. Thus, sentences such as (52) and (53) could be taken to show that the epistemic phrase is to the left of negation while the deontic (alternatively, "alethic") is to the right.

Dapat hindi sila dapat mag-aral must NEG 3p.SUB must AV.INF-study

'It should be that they do not have to study.'

(53) Maaaring hindi sila maaaring mag-aral can-LNK NEG 3p.SUB can-LNK AV.INF-study 'It is possible that they are unable to study.'

As Ernst notes, this necessarily treats the formal similarity between epistemic and deontic modals across languages as accidental homophony. ${ }^{9}$ It appears more felicitous to treat modals as yielding an epistemic reading when taking a higher FEO complement (i.e. Proposition) and a deontic reading when taking a lower FEO complement (i.e. Event). Therefore, when modals are stacked on one side of the predicate, the outer modal may only receive an epistemic reading while the inner modal, a deontic one.

It must also be noted that many deontic/alethic modals in Tagalog (as in many other languages, cf. de Haan 1997) can appear on either side of negation with transparent scope relations, as found in (54-55).

(54) Puwede akong hindi ma-tulog.

can 1s.SUB-LNK NEG STA.INF-sleep

'I'm able to not sleep.' (deontic $c a n>N E G$ ) 
(55) Hindi ako puwedeng ma-tulog.

NEG 1s.SUB can-LNK STA.INF-sleep

'I'm unable to sleep.' (NEG > deontic can)

Thus, a multiple base generation approach must still rely on movement to capture all the facts while a free adjunction approach accounts for the freedom and scope transparency simultaneously.

\subsection{Conclusion and prospects}

The evidence presented here argues strongly for a Relative approach to adverbs along the lines of Ernst 2002. Because Tagalog has a wide variety of means for introducing adverbs into the clause and a large number of clitic adverbs, we were able to differentiate between different predictions made by Cinque and Ernst in regard to multiple adverb facts. It was seen that a syntactic (Relativized Minimality) account of certain ungrammaticalities fails in Tagalog while a more semantically based account explains the data parsimoniously. Evidence was also shown in support of treating concentric effects as the norm in adverbial interpretation. Under this view, right adjunction is necessary to account for the different interpretive possibilities of adjuncts on the right edge of the clause.

Taking concentric layering to be a natural outcome of the FEO calculus, the "inverse" ordering of adverbs in Malagasy (Rackowski 1998) and Seediq (Holmer this volume) in the postverbal domain is less surprising then previously considered. The following order for Malagasy adverbs in relation to the verb is given by Rackowski (1998) as (56).

$$
\begin{aligned}
& \mathrm{Na}(\text { dia })>\text { Matetika }>T S y>\text { Efa } / \text { Mbola }>T s y>\text { VERB }>\text { Tsara }> \\
& \text { 'Even' } \begin{array}{l}
\text { generally NEG already still NEG } \\
\text { wanteraka }>\text { Foana }>\text { Intsony }>\text { Mihitsy }>A z a>V e
\end{array} \\
& \text { completely always anymore at-all though SPEECHACT (Q) }
\end{aligned}
$$

In the preverbal domain the adverbs are ordered as predicted by Cinque's hierarchy but in the postverbal domain the order appears to be reversed.

Concentric effects are clearer in Malagasy than in Tagalog since Malagasy has few or no mitigating prosodic factors such as (prosodically determined) clitic movement. Furthermore, Malagasy seems to treat all adverbs similarly in terms of how they are introduced into the clause; topicalization and other peripheral positions are less common than in Tagalog. Taking this into account, the FEO predicts this order naturally in a verb initial language. Additionally, there is evidence that adverbs within a single class are in fact permutable in Malagasy with corresponding differences in scope (cf. Rackowski 1998:10). Adverb order should therefore not be taken as a strong argument for a "roll-up"/intraposition derivation (Pearson 2001) in-lieu of evidence that it is possible for a verb-initial language to display the Cinque order of adverbs in the postverbal domain. 


\section{Endnotes}

ACKNOWLEDGEMENT: This paper benefited from comments by John Whitman, John Wolff, Draga Zec and the audience at AFLA XI.

1. Cinque allows for unmotivated movement through an extensive array of functional projections and multiple loci for base generation of certain adverbs. Ernst on the other hand introduces stipulatory syntactic features such as [+Right] which is satisfied by linearization to the right of a certain head and PF requirements on "heavy/light" items which have no basis in the phonological content of the items themselves.

2. I choose these terms over the more common Tight-fit versus Loose-fit since these terms underemphasize a crucial distinction between the two approaches: the predictions of relative scope between adverbs.

3. Relativized Minimality as envisioned in Rizzi 2002 takes the more specific categories quantificational, modificational, topic and argument to be relevant in calculating minimality.

4. It must be noted that the judgments above can also be predicted by Emst's theory since a frequency adverb must take an Event as its FEO complement while a modal adverb such as probably raises the FEO type to Proposition, which cannot be subsequently lowered to satisfy the outer adverb. Although the two theories cannot be differentiated on the basis of the above data, there are, in principle, cases which force different predictions from these two approaches as will be shown later.

5. Of course, these "types" of movements have all been taken to be instantiations of a single rule since the advent of GB. The empirical prediction underlying the rejection of "adverb movement" as an independent phenomenon is that adverbs which are not interpreted in their surface position are displaced because of positional requirements on topicalized, focused or wh-constituents.

6. Abbreviations used: AV - actor voice; COMP - complementizer; EMPH emphatic; EPST - epistemic; GEN - genitive; IMPF - imperfective aspect; INF infinitive; IRR - irrealis; LNK - linker; LV - locative voice; NEG - negation; NOMZ - nominalizer; OBL - oblique case; OPT - optitative; P persona1/[+human] (case marker); PL - plural; POL - politeness marker; PV patient voice; Q - question marker; RHET - rhetorical question marker; STA stative; SUB - 'subject' (absolutive/nominative case); SURP - surprise; TOP topic marker; TR - transitive;

7. Clitics can intervene since they are ordered post-syntactically.

8. There is no evidence from binding or word order in Tagalog for a rollup/intraposition derivation as Pearson (2001) posits for Malagasy and other "inverse" predicate initial-languages.

9. More recently, Cinque (2004) addresses the homophony problem by suggesting that certain adverbs are 'underspecified' for certain features (e.g. epistemic/deontic) and can thus be compatible with two different positions. However, the fact that these 'underspecified' adverbs are still base-generated separately leaves open the question of what, precisely, their connection is.

\section{References}


Alexiadou, Artemis. 1997. Adverb placement. Amsterdam: John Benjamins.

Andrews, Avery. 1983. A note on the constituent structure of modifiers. Linguistic Inquiry 14. 695-697.

Cinque, Guglielmo. 1999. Adverbs and functional heads: a cross-linguistic perspective. Oxford: Oxford University Press.

Cinque, Guglielmo. 2004. Issues in adverbial syntax. Lingua 114. 683-710.

Ernst, Thomas. 1984. Towards in integrated theory of adverb position in English. Bloomington, $\mathbb{N}$ : Indiana University Linguistics Club.

Ernst, Thomas. 2002. The syntax of adjuncts. Cambridge: CUP.

Ernst, Thomas. 2004. Principles of adverbial distribution in the lower clause. Lingua 114. 755-777.

de Haan, Ferdinand. 1997. The interaction of modality and negation. New York: Garland Press.

Hale, Kenneth, Keyser, Samuel-Jay. 1993. On argument structure and the lexical expression of syntactic relations. The view from building 20 . Eds. Kenneth Hale and Samuel-Jay Keyser. MIT Press, Cambridge, MA, pp. 53-109.

Holmer, Arthur. 2004. Interposition and Formosan adverbial heads. This volume.

Jackendoff, Ray. 1972. Semantic interpretation in generative grammar. Cambridge, MA: MIT Press.

McConnell-Ginet, Sally. 1982. Adverbs and logical form: a linguistically realistic theory. Language 58. 144-84.

Pearson, Matthew. 2001. Two types of VO languages. VO and OV, ed. Peter Svenonius.

Rackowski, Andrea. 1998. Malagasy adverbs. The structure of Malagasy, volume II, ed. Ileana Paul, UCLA Working Papers in Linguistics.

Rizzi, Luigi. 1990. Relativized minimality. Cambridge, MA: MIT Press.

Rizzi, Luigi. 2002. Locality and left periphery. ms, University of Siena (to appear in Belletti, A. (Ed.) (in press).

Svenonius, Peter. 2001. The derivation of VO and OV. Amsterdam: John Benjamins.

Daniel Kaufman

Department of Linguistics

Cornell University

Ithaca, NY 14853-4701 U.S.A.

dak37@cornell.edu 